\title{
Feminismos e interseccionalidad: aportes para pensar los feminismos lésbicos centroamericanos
}

\author{
Marisol Fournier-Pereira ${ }^{1}$
}

\section{Resumen}

Recepción: 29 de abril de 2014 / Aprobación: 25 de julio de 2014

Este ensayo propone una lectura crítica de las principales discusiones y tendencias políticas de los feminismos lésbicos en Centroamérica desde una perspectiva interseccional. A través del análisis de las metáforas del cuarto propio y el jardín abierto, utilizadas como figuras retóricas por las dos principales corrientes del lesbofeminismo latinoamericano, así como la revisión de las discusiones que activistas centroamericanas lesbianas y trans con respecto a estas posturas, se propone la interseccionalidad como una herramienta para los procesos de construcción de los feminismos lésbicos centroamericanos.

\section{Palabras clave}

Feminismo lésbico; interseccionalidad; trans; ELFLAC; Venir AI Sur

\section{Abstract}

This essay proposes an intersectional critical analysis of the main discussions and political trends of lesbian feminisms in Central America. The analysis of the metaphors "a room of one's own" and the "open garden", used as rhetorical figures by the two main currents of Latin American lesbian feminisms, as well as the review of the dis $\neg$ cussions that Central American lesbians and trans activists around these positions, intersectionality is proposed as a tool for the construction process of Central American lesbian feminists.

\section{Keywords}

Lesbian feminism; intersectionality; trans; ELFLAC; Venir Al Sur

1 Costarricense. Licenciada en Psicología por la Universidad de Costa Rica (UCR), actualmente cursa la Maestría en Comunicación y Desarrollo en la misma institución. Docente e Investigadora en la Escuela de Psicología, Escuela de Ciencias de la Comunicación Colectiva, Centro de Investigación y Estudios Políticos de la UCR. Correo electrónico: sol.ucr@gmail.com 


\section{Resumo}

Este ensaio propõe uma leitura crítica das principais discussões e tendências políticas dos feminismos lésbicos na América Central desde uma perspectiva interseccional. Através da análise das metáforas "um quarto só para si" e "o jardim aberto", utilizado como retórica pelas duas principais correntes do feminismo lésbico da América Latina, bem como a revisão das discussões de ativistas lésbicas e trans da América Central sobre estas posições, propõe-se a intersetorialidade como uma ferramenta para o processo de construção dos feminismos lésbicos na América Central.

\section{Palavras chave}

Feminismo lésbico; intersetorialidade; trans; ELFLAC; Venir al Sur

\section{Introducción}

ste ensayo busca hacer una lectura crítica de los feminismos lésbicos en Centroamérica desde una perspectiva interseccional. Se propone un recorrido por las principales corrientes lésbico feministas latinoamericanas y sus nudos de conflicto, interpelándolas desde una perspectiva interseccional, como punto de partida para pensar los retos pendientes y posibilidades para la construcción de feminismos lésbicos centroamericanos.

Este texto no pretende erguirse como una voz autorizada y creadora de una verdad. Por el contrario, asume una posición crítica y autocrítica de ese lugar de saber/poder (Foucault, 1993) que se adjudica la potestad de nombrar y narrar la realidad desde un lugar irrebatible, y se auto-confiere la autoridad para dar cuenta de fenómenos sociales de forma sólida y contundente.

En contraste, este ensayo se escribe desde un lugar subalterno e inacabado. No busca la asepsia del positivismo, ni pretende dar cuenta de la totalidad de discursos que construyen el tejido social que interpela. La realidad se entiende aquí como un proceso, un continuum que no tiene ni final ni inicio, sino que es un devenir cambiante producto de la construcción que provoca la interacción entre sujetos. Es precisamente este proceso y su potencial para perpetuarse y transformarse, el principal interés de estas reflexiones.

En línea con las premisas fundamentales del Análisis Crítico del Discurso (Fairclough y Wodak, 1997), se asume que la producción académica no es neutral. Esta no debería significar un riesgo para la rigurosidad, pero sí un reto para sostenerla y garantizarla al acercarse a un objeto, necesariamente siempre, desde una posición determinada (en este caso, el interés por la interseccionalidad y sus posibles aportes para la deconstrucción y construcción de los feminismos lésbicos centroamericanos). 
Desde este encuadre, este texto más que datos contundentes presenta fisuras y puntos de inflexión, más que un discurso hegemónico explora los diálogos y debates, y más que resultados, aporta interrogantes para la reflexión desde la academia y desde los movimientos feministas.

\section{Conozca a su interlocutorx ${ }^{2}$}

Anneliese Singh, Kate Richmond y Theodore Burnes (2013), en su artículo Feminist Participatory Action Research with Transgender Communities: Fostering the Practice of Ethical and Empowering Research Designs, señalan como punto inexorable en el desarrollo de la Investigación-Acción-Participativa (IAP) desde un marco ético, la necesidad de responder, antes de comenzar cualquier proceso, a dos preguntas fundamentales: ¿quién soy yo? y ¿cuál es mi relación con mi interés de investigación?

Si bien este ensayo no parte de un proceso de IAP, sino que se construye a partir del Análisis Crítico del Discurso desde una perspectiva interseccional, estas preguntas resultan, de igual forma, válidas e importantes en términos de transparencia y son un intento por alivianar la investidura de poder que inevitablemente otorga la academia.

Explicitar quién escribe y desde qué lugar, no busca ser un ejercicio egocéntrico. Por el contrario, es un esfuerzo por reconocer los propios privilegios, no para librarse de ellos, sino para trabajarlos de forma crítica y minimizar los sesgos que conllevan. Soy joven, de clase media, docente e investigadorx en la Universidad de Costa Rica, interesadx en la interseccionalidad, las prácticas decoloniales, las disidencias sexuales y de género, y los feminismos críticos, tanto desde la academia como desde el activismo.

Me interesa la investigación de los feminismos en América Latina, no solamente por la pasión académica, sino como herramienta para apoyar procesos de construcción de feminismos centroamericanos autónomos. En esta línea, estoy vinculadx con uno de los procesos que este ensayo analiza: la organización del II Encuentro LesBiTransInter Feminista, que se realizará en Costa Rica en mayo de 2015. Desde dicho lugar escribo este ensayo, que no busca tomar una posición que favorezca una u otra tendencia, sino más bien, procura hacer una reflexión crítica de las fortalezas y limitaciones de cada propuesta política, con la intención de que constituya un aporte para los feminismos lésbicos centroamericanos.

2 Se colocó una "x" para referir el género de quien escribe no para complicar la lectura desde una moda posmoderna. Esa " $x$ " representa aquí una función, en el sentido matemático. Es decir, representa ese espacio en la ecuación que puede ser llenado con diversas formas, entendiéndose no tanto mujer y hombre, sino en especial todos los intersticios que no caben entre esas letras. Se pensó como función, móvil, activa, flexible, porque es así como funcionan el biopoder, la represión, el autoritarismo. Esa "x" representa no solo un género, sino las múltiples identidades que lo acompañan, que a su vez son las marcas que visibilizan cómo operan los distintos sistemas de opresión. 


\section{Desarrollo de los feminismos lésbicos en América Latina}

Intentar resumir la historia de los feminismos lésbicos latinoamericanos en el limitado espacio de este apartado sería, no solo pretencioso, sino imposible. Los feminismos, como prácticas de resistencia y articulación, existen en la región desde antes de que siquiera se nombraran de esa forma, antes de que se inventaran los términos para nombrar el sistema patriarcal y la heteronormatividad como jerarquías de poder, y antes incluso de que Abya Yala fuese colonizada y bautizada como América Latina.

En este sentido, esta recapitulación no pretende ser un registro acabado, mas procura dibujar el contexto en que se construyen hoy los feminismos lésbicos en América Latina, con una mirada particular en Centroamérica. Como punto de partida, cabe abrazar una premisa que Rachid, Espinosa, y Gonorasky afirman para referirse al feminismo autónomo, y que es válida para los movimientos lésbico feministas: "como dentro de todo movimiento, no hay posturas únicas, no hay respuestas que satisfagan a todxs, y las necesidades mismas van variando" $(2008,1)$. Asimismo, comprendemos que los movimientos sociales y las corrientes teóricas con que dialogan no surgen de forma aislada y espontánea, sino que son el resultado de las relaciones dialécticas en un determinado contexto. En esta línea, hablar del feminismo lésbico implica, necesariamente, hablar de otras corrientes del feminismo con las que dialoga, o bien, frente a las que se contrapone.

Según Espinosa (2012), el nacimiento del lesbofeminismo como corriente de pensamiento y acción colectiva se ubica entre finales de la década de 1960 e inicios de la de 1970, con una marcada línea crítica frente al feminismo universalista que no respondía a las necesidades y preocupaciones de las realidades lésbicas.

Jules Falquet (en Torres, 2012), habla de tres grandes olas del feminismo lésbico: el lesbianismo feminista (que lanza una crítica al feminismo heterosexual y denuncia la lesbofobia como estrategia de reproducción del sistema de opresión), el lesbianismo radical (que rompe con la opresión masculina a partir de la ruptura con las relaciones heterosexuales de dominación) y el lesbianismo separatista (que lucha por construir espacios exclusivos para mujeres lesbianas).

En esta línea, en la década de 1980 surgen en Latinoamérica espacios lésbicos con fines lúdicos y políticos, como el caso de las Entendidas en Costa Rica (Torres, 2012) y, probablemente, muchos otros similares a estos en el resto de países. Así, en 1987 se celebra en México el I Encuentro Lésbico Feminista de América Latina y el Caribe (ELFLAC), en palabras de Norma Mogrovejo:

Ante la necesidad de las lesbianas latinoamericanas de encontrar un es- 
movimiento homosexual y en la izquierda fue difícil que la especificidad lésbica y la crítica al heterocentrismo patriarcal obtuvieran eco $(2012,1)$.

Desde entonces, se han celebrado nueve encuentros en distintas latitudes de América Latina y el Caribe. En dos ocasiones, países centroamericanos han sido sede del ELFLAC: Costa Rica en 1990, en un contexto de gran hostilidad y violencia lesbófoba, que incluso involucró al entonces ministro de Gobernación, Antonio Álvarez Desanti, quien emitió una directriz para que no se otorgaran visas a mujeres que viajaran solas a Costa Rica, pues serían sospechosas de participar en el II ELFLAC. Veinte años después, en el 2010, Guatemala alberga al VIII ELFLAC que, como se verá más adelante, marca el punto de inflexión que inscribe una bifurcación en el movimiento alrededor de estos encuentros.

Torres (2012) señala que en las décadas de 1990 y principios del siglo $\mathrm{XXI}$, surgen también críticas a las corrientes lésbico-feministas, por tener un sustento academicista, blanco, occidental y de clase media, que dificulta la incorporación de mujeres que sufren distintas formas de opresión basadas en clase, raza, etnicidad, edad, lugar de residencia, entre otras.

Esta crítica que podríamos denominar interseccional, como señalan Torres (2012) y Espinosa (2012), es acogida por los movimientos lésbico-feministas, que hasta la actualidad intentan construir discursos (con distintos resultados en la práctica) atravesados por reflexiones críticas en torno a las distintas formas de opresión producto del heteropatriarcado capitalista neoliberal.

Parte de este esfuerzo crítico y autocrítico por incorporar la discusión interseccional, puede observarse tanto en los ejes de los últimos ELFLAC, como en los del encuentro LesBiTransInter Feminista Venir AI Sur, la preocupación por discutir temas como:

Cómo pensamos y actuamos frente el régimen heterosexual, el patriarcado, el racismo, el militarismo, las políticas neoliberales neocoloniales y otras opresiones, a partir de un análisis global, nacional y local, de forma imbricada y atravesando nuestras experiencias (ELFLAC, 2014).

Acción LesBiTransInter Feminista en contextos de militarización, conflictos armados internos, neoliberalismo, lesbofobia, transfobia, migración o desplazamientos forzados, etc. (Comisión de Metodología y Contenidos Venir Al Sur, 2011).

Sin embargo, la inclusión de estos temas en el discurso no implica que, necesariamente, se superen las contradicciones internas y las lógicas de dominación que pesan sobre las prácticas sociales. Así, por ejemplo, señala Marian Pessah que en el VIII ELFLAC "las lesbianas negras se sintieron -y de hecho lo fueron- discriminadas y atravesadas por la blanquitud predominante en el encuentro" (2012, 26), e incluso optaron por autogestionarse un espacio dentro del encuentro para discutir desde su lugar como lesbianas feministas negras.

También señala Pessah, en tono de autocrítica, que el problema de la inclusión no se resuelve (aunque es uno de sus componentes) con acercar los 
espacios de encuentro a las localidades afro o indígenas, y pregunta: "¿qué pasó que un ELFLAC realizado en Guatemala, cuya población indígena supera el 70\%, solo hubieran 3 lesbianas asumidamente indias-indígenas?" (2012, 27). No se trata de un problema meramente geográfico, sino que es un problema que nace del lugar de privilegio desde el que se construye el discurso.

Con esta crítica planteada por Pessah, se coloca en la discusión la necesidad de mover la mirada más allá del sujeto lésbico y feminista, sino de reconocer las diversidades de lesbianas y de feminismos en América Latina, entendiendo que esta reducción que unifica a las lesbianas feministas, pierde la perspectiva de las múltiples formas de opresión y resistencia.

En esta línea de discusión sobre la necesidad de una mirada crítica y autocrítica en lesbofeminismo, el diálogo que establece Espinosa (2012) con el desarrollo de los movimientos feministas autónomos resulta esclarecedor. El feminismo autónomo, en palabras de Espinosa (2012), busca:

Un acercamiento a otra forma de comprensión de los sistemas de opresión y subordinación de las mujeres y de grupos subalternizados, incorporando los análisis sobre la colonialidad del poder y la violencia epistémica, para explicar la manera en que el patriarcado moderno surge y es correlativo a otros regímenes de poder como el de la heterosexualidad, la ideología racista y la explotación capitalista dentro del proceso histórico de la conquista y coIonización de América (116).

A mediados de la década de 1990, en un contexto de "institucionalización y tecnocratización creciente del feminismo regional de la mano del proceso de oenegización, de entrada al Estado y de la agenda transnacional impulsada desde las Naciones Unidas y la cooperación internacional" (Espinosa, 2012, 115), surge una respuesta crítica y radical que da pie a que varias lesbofeministas se autodenominen feministas autónomas, en clara oposición a las relaciones de dependencia que la cooperación implica.

Sin embargo, en la década siguiente, de la mano con una nueva generación de feministas autónomas, parte de estas posturas se flexibilizan, y el rechazo total y absoluto a la cooperación se relativiza en tanto se reconoce que, canalizado cuidadosamente y poniendo especial atención en los microprocesos de colonización y control, pueden convertirse en una herramienta para la articulación de las resistencias (Espinosa, 2012).

El feminismo lésbico latinoamericano se nutre de estas discusiones. Así, por ejemplo, la organización de los ELFLAC, de Venir al Sur, así como el accionar cotidiano de muchas de las organizaciones lésbico-feministas en América Latina, se apoya en la cooperación para el financiamiento, pero se sostiene en una postura de crítica y de reflexión que busca defender la autonomía política del movimiento (Mogrovejo, 2010).

De forma similar, el rechazo que, inicialmente, fue muy radical hacia toda forma de institucionalización (Espinosa, 2012) y hacia el trabajo en la 
línea de reconocimiento de derechos, se ha convertido hoy en una de los principales focos de debate y tensión para los movimientos lésbico-feministas, con una serie de matices en la práctica. Espinosa señala que esta nueva generación de feministas radicales construye su accionar, más que sobre certezas inquebrantables, sobre el diálogo y el debate permanente desde posiciones críticas. Desde este lugar, surge:

Cierto reconocimiento de la necesidad de asegurar un estado de derecho con sus instituciones que proteja contra las politicas neoliberales y de mercado, sin que eso niegue o deje de reafirmar la necesidad de la existencia de movimientos vivos, fuertes, antisistémicos, autónomos y diferenciados a estos aparatos institucionales (Espinosa, 2012, 116).

Se trata de discusiones que no pretenden ser acabadas, sino fuegos vivos que alimenten el motor de los movimientos. Constituyen focos de tensión y contradicciones que retan a los movimientos en su afán por conjugar la resistencia decolonial, en un contexto que ha sufrido una penetración colonial tan violenta, y que hoy se sostiene a través de mecanismos culturales y estructurales, de los que, la cooperación internacional y las tendencias hegemónicas del feminismo producido en las academias del norte global son un vivo ejemplo (Grosfoguel, 2011).

Finalmente, en este recorrido por las principales líneas de discusión de los feminismos lésbicos en América Latina, aparece el punto que, al menos en la última década, ha constituido el mayor foco de discrepancia entre las grandes tendencias del movimiento: el "debate interno acerca de la categoría mujeres, la política de identidad y la política de la sexualidad que evidencia, en los posicionamientos autónomos y radicales mismos, distintas comprensiones respecto de la naturaleza de la opresión sexual” (Espinosa, 2012, 116).

La discusión en torno a la categoría mujer, remite a la discusión sobre el sujeto político del feminismo lésbico. Quizás el punto donde aparecen mayores concordancias es en torno al cuestionamiento de una forma impuesta del "ser mujer", construida desde y al servicio del lugar de poder masculino, con una serie de mandatos y prohibiciones que se imponen como naturalizados (Wittig, 2006). La identidad lésbica-feminista como identidad política, en este sentido, constituye una ruptura con esa forma única de ser mujer, que resulta opresiva y funciona como una herramienta de control y dominación (Torres, 2012). Así, como señalan Rachid, Espinosa y Gonorasky, si bien el feminismo como herramienta de lucha contra la opresión de las mujeres constituye el origen,

El lesbofeminismo ha pasado a cuestionar fuertemente la noción misma de "mujer" (con teóricas como Monique Wittig o Adrienne Rich), lo cual cambia la óptica desde la cual se plantea el problema: el problema deja de ser qué nos pasa a las mujeres en tanto que oprimidas, sino que pasa a ser cómo se construye el sujeto mujer y qué alternativas tenemos $(2008,2)$. 
No obstante, dentro de esta discusión aparecen posturas contrapuestas, y en apariencia irreconciliables, en torno a cómo se define el sujeto político del feminismo, qué define el ser mujer y el ser lesbiana. En un extremo, una posición sostiene que las categorías mujer y lesbiana están indiscutiblemente determinadas por un cuerpo político sexuado (con una fisionomía femenina), y en el otro extremo quienes cuestionan esta posición por considerarla esencialista, y apelan a la autodeterminación y la posibilidad de deconstruir y construirse críticamente como mujer y lesbiana en cuerpos con fisionomías diversas e incluso cambiantes. Desde este lugar, lo lésbico feminista se asume como un lugar de enunciación política que cuerpos diversos pueden abanderar, sin que sea de dominio exclusivo de las bio-mujeres.

Este es el detonante que provoca una explosión en el VIII ELFLAC, celebrado en Guatemala en el año 2010, que marca un quiebre en el movimiento a partir del cual surgen dos grandes tendencias (que incluso organizan encuentros de forma separada desde entonces): aquellas que defienden la exclusión de personas trans de los espacios lésbico-feministas, por considerarlas una amenaza a la autonomía del espacio y una imposición de las agencias de financiamiento, y aquellas que defienden la inclusión de personas trans que se identifican con el feminismo lésbico, en aras de tejer articulaciones entre diversos cuerpos y subjetividades alrededor del feminismo lésbico en diálogo con feminismos trans, inter y bi.

\section{El cuerpo político como punto de inflexión del feminismo lésbico latinoamericano}

\section{Análisis de metáforas}

Lakoff y Johnson afirman que nuestro sistema de pensamiento, nuestras comunicaciones diarias y nuestra cultura están basadas en metáforas de la vida cotidiana: "nuestro sistema conceptual ordinario, en términos del cual pensamos y actuamos, es fundamentalmente de naturaleza metafórica" (1995, 2). Sin embargo, el Análisis Crítico del Discurso llama la atención sobre aquellas metáforas que más allá de su función ilustrativa, se utilizan con una intensión persuasiva; "una retórica de este tipo tiene asimismo una dimensión más empírica, la que estudia los aspectos sociopsicológicos de la persuasión basados en el uso de estructuras retóricas específicas (Van Dijk, 1990, 50).

Dentro de las dos grandes tendencias del lesbofeminismo, encontramos la utilización de metáforas como recurso retórico: la del cuarto propio en el caso de la tendencia que defiende la no inclusión de las personas trans, y la del jardín abierto, en el caso de quienes defienden la apuesta les-bi-trans-inter feminista. 
A continuación, se presenta un análisis crítico de ambas metáforas desde una perspectiva interseccional, y desde esta misma perspectiva, a modo de conclusión, se propone una tercera metáfora para interpelar a ambas corrientes.

\section{Metáfora del cuarto propio}

Nosotras como Ekipa le apostaremos a construir estos espacios más reducidos, con otras cómplices a las cuales también les interese partir de la necesidad de mantener un "cuarto propio" como lesbianas feministas, para pensarnos, sentirnos, expresarnos, recuperar la memoria de nuestras luchas, recuperar la palabra propia, el horizonte propio, el vínculo entre nosotras, la noción de nuestros cuerpos y del deseo lésbico como constituyente de un desacato al patriarcado (Ekipa Guatemala, 2010b, 2).

La metáfora del cuarto propio es frecuente en las comunicaciones oficiales de esta tendencia. En un diálogo intertextual, el cuarto propio alude al ensayo de Virginia Woolf "A Room of One's Own", el cual se ha convertido en un clásico del feminismo que sostiene la importancia de tener espacios propios de las mujeres donde se puedan construir las transformaciones culturales y las condiciones materiales para su emancipación de la opresión patriarcal.

Un cuarto propio, en este caso, alude a la necesidad de contar con espacios de discusión y articulación sobre el lesbofeminismo, entre lesbianas feministas. Dentro de esta habitación, se construyen las agendas y se articulan las prácticas de resistencias desde el feminismo lésbico, que son cercanas a las de otros feminismos, pero no iguales. Así, dentro de este espacio las demandas de las mujeres lesbianas, no se pierden ni se disipan entre demandas del feminismo hegemónico ni dentro de las discusiones más amplias del movimiento LGBT.

Los ejes temáticos de los últimos ELFLAC y la convocatoria para el que se realizará en octubre de 2014, dan cuenta de una preocupación interseccional por abordar los conflictos cotidianos que afectan a mujeres lesbianas, de forma contextualizada, desmontando los engranajes que existen entre el heteropatriarcado y sistemas de opresión como los procesos de militarización, el racismo, la colonialidad, el neoliberalismo, entre otros.

Sin embargo, al lado de las posibilidades que brinda el cuarto propio, vale la pena explorar las complicaciones que conlleva. Al desmenuzar los componentes de esta metáfora, encontramos el sustantivo "cuarto". Según la Real Academia Española (2001), es un sinónimo de habitación, es decir, "en una vivienda, cada uno de los espacios entre tabiques destinados a dormir, comer, etc.". Un aposento es, por lo general, un espacio delimitado por paredes que tiene la posibilidad de cerrarse y mantenerse separado del resto de espacios de una casa.

La imagen del cuarto, en este sentido, funciona como una suerte de protección, una barrera que permite resguardar adentro aquello que no se quiere dejar expuesto afuera. En la BoletinA que publica la Ekipa de Guatemala 
(2010a), una publicación del VIII ELFLAC que resume las principales posiciones alrededor del tema, algunas de las principales defensoras de esta tendencia, como Julieta Paredes, Norma Mogrovejo, Janaína R, Chuy Tinoco y Claudia Acevedo coinciden en que lo que se quiere resguardar en el cuarto es precisamente el feminismo lésbico (sus discusiones, sus estrategias de lucha, sus agendas, su lugar de enunciación), y se quiere proteger del afuera donde se soplan con fuerza los vientos de la misoginia, la heteronormatividad y la dominación patriarcal, pero también los de la diversidad sexual y las luchas LGBT ${ }^{3}$. Estos últimos, advierten las autoras, se presentan como aparentes aliados en las luchas lesbofeministas; sin embargo, constituyen amenazas solapadas que difuminan las particularidades de la identidad política lésbica, atentan contra la cohesión del movimiento, y dispersan el enfoque feminista de lucha.

Continuando con el análisis, el sustantivo cuarto es acompañado en esta metáfora, por el adjetivo "propio". Según la Real Academia Española (2001): "perteneciente o relativo a alguien que tiene la facultad exclusiva de disponer de ello". En este sentido, cabe preguntar qué es aquello de lo que se dispone de forma exclusiva: ¿son los espacios de encuentro, el lugar de enunciación o la articulación de la resistencia lesbofeminista? Estas preguntas resultan fundamentales pues, como toda relación de propiedad implica una relación de poder, la forma en que se define y se asume esta propiedad determina un posicionamiento frente al inevitable ejercicio del poder.

La importancia de espacios autónomos y cerrados de discusión y articulación es comprensible en términos de la necesidad de establecer agendas y prioridades a partir de las particularidades de la existencia lésbica, desde una perspectiva feminista. Sin embargo, el reto fundamental gira en torno a cómo trabajar los parámetros que definen la identidad lesbofeminista para evitar que se torne en una política restrictiva.

Una lectura del poder desde la interseccionalidad preguntaría entonces de qué están hechas las paredes de ese cuarto y cómo se definen los criterios de inclusión, para que el interés por resguardar los espacios de construcción del feminismo lésbico, no termine, por efecto de rebote, jerarquizando identidades y cuerpos, e inscribiendo dinámicas de exclusión.

Una pregunta pendiente que refleja la necesidad de discutir en torno a la construcción de identidades de género e identidades a partir de la resistencia a la heteronormatividad patriarcal. Sin duda, existen puntos compartidos y zonas grises entre ambas, pero como señalan autoras como Butler (2006) y Rubin (1986), son finalmente distintas. Desde este nodo de conflictividad surgen desafíos complejos que no encuentran respuestas únicas dentro de los movimientos

3 Estas autoras hacen una diferencia entre la agenda LGBTI, que reconoce las identidades pero las aglutina en un combo amplio donde la particularidad de la $L$ se pierde con frecuencia, y el concepto de diversidad sexual, donde el reconocimiento de las identidades se torna más difuso y ambiguo. 
lésbico feministas ${ }^{4}$, como qué hacer frente al reclamo de algunas personas trans (con cuerpos y genitalidades diversos) que se autodefinen como lesbianas y piden el reconocimiento como lesbofeministas.

Volviendo a la metáfora del cuarto propio, desde una lectura interseccional, el problema no radica en la necesidad de contar con espacios propios (de hecho, la interseccionalidad parte del reconocimiento de cada una de las identidades y las dinámicas de opresión que las atraviesan). El cuarto propio se torna problemático cuando el sentido de propiedad se enmarca desde la lógica de la propiedad privada (que ha sido tan criticada por los feminismos de izquierda), y se erige como un espacio que hay que defender del resto de habitantes de cuartos vecinos que automáticamente se convierten en potenciales enemigos.

En una crítica a este discurso, elaborada desde la otra corriente que defiende la inclusión trans, Ramírez y Castellanos afirman que este cuarto: "al ser reapropiado por el lesbianismo feminista 'oficial' implica actos de propiedad: vigilancia y custodia de las entradas, reconocimiento de la autoridad de sus dueñas, señalamiento y expulsión de lo ‘ajeno'” $(2013,43)$.

Dentro de los movimientos señalados como enemigos, el colectivo trans es el que se ha marcado como más peligroso. Como se verá más adelante, esto podría deberse, paradójicamente, a que en algunos puntos es el más cercano. Por ejemplo, existen trans que se autodenominan como lesbianas y se identifican con las luchas feministas, y a partir de ahí han buscado acercarse a los espacios de articulación del feminismo lésbico.

Desde esta posición, se defiende la no participación de las personas trans, en tanto se les considera como una amenaza para el propio movimiento lésbico-feminista. Ramírez y Castellanos citan un artículo de Yan María Yaoyólotl, que circuló durante el VIII ELFLAC en Guatemala, en el que se afirma: "la invasión de la transexualidad (Caballo de Troya) está tratando de destruir la autonomía del movimiento feminista, la autoorganización de las mujeres por su emancipación" $(2013,45)$.

El riesgo con este tipo de retórica guerrerista en esta metáfora, es que, entendiendo el discurso como práctica social (Fairclough y Wodak, 1997), y retomando los múltiples esfuerzos que el feminismo ha hecho por reconocer el discurso como una forma de violencia, se crea un contexto de polarización y hostilidad proclive a la confrontación. En efecto, representantes de ambas tendencias denuncian con pesar situaciones de violencia vividas en el VIII ELFLAC. Según afirman Ramírez y Castellanos (2013), durante el VIII ELFLAC

$4 \quad$ Incluso dentro de las voces más reconocidas en los ELFLAC, se encuentran distintas posturas sobre cómo abordar estos temas, con posturas que van desde la total oposición a la inclusión de personas trans, como es el caso de Norma Mogrovejo, hasta quienes, siempre desde el reconocimiento de la necesidad del cuarto propio, insisten en el riesgo del aislamiento y hacen un llamado a buscar formas de diálogo y articulación, como es el caso de Yuderkis Espinosa (Ekipa Guatemala, 2010a). 
sucedieron agresiones verbales y simbólicas contra Michel Riquelme ${ }^{5}$, que comenzaron cuando la Ekipa organizadora le advirtió que no podían garantizarle seguridad en tanto su presencia generaba hostilidad y hacía sentirse violentadas a varias participantes, y culminaron con abucheos y descalificaciones cuando intentó hablar en una plenaria (50).

Desde el otro bando, Marian Pessah (2010) afirma que varias participantes se sintieron agredidas por la reacción de quienes apoyaban a Riquelme, que consistió en pegarse carteles en el pecho que decían "Todxs somos trans". Esta afirmación, señala Pessah, fue interpretada por muchas como una afrenta contra su identidad lésbica.

Estas formas de violencia, tan criticadas desde los feminismos cuando son perpetuadas por hombres y estructuras patriarcales, en este caso aparecen enmarcadas, y de alguna forma justificada o aminorada, por una retórica de guerra, en la que la defensa de la propiedad privada debe sostenerse a toda costa.

Es importante insistir en que esta no es necesariamente la posición de todas las participantes de los ELFLAC, y reconocer las ya mencionadas diferencias incluso entre de las interlocutoras del ELFLAC. Existen dos grandes tendencias contrapuestas dentro del feminismo lésbico latinoamericano, y en medio, existe una serie de posiciones que dialogan con ambas posturas. Es, además, una discusión que se retoma, se profundiza y se reelabora en el tiempo, y las posturas de un lado y de otro van adoptando nuevos matices. Sin embargo, sin un afán totalizante, se analiza esta posición en tanto se autoriza como voz oficial de la Ekipa organizadora del VIII ELFLAC, donde este conflicto constituyó la discusión principal.

A la luz de estas reflexiones, cabe cuestionar si la metáfora del cuarto propio es la más adecuada para dar cuenta de la forma en que se materializa esta propuesta en la práctica. Una habitación, en principio, forma parte de un espacio mayor que sería la casa. En la casa pueden existir otros cuartos privados (ciertamente importantes), pero también existen espacios comunes: la cocina, la sala, el corredor. Son espacios de encuentro que suponen la convivencia en colectivo. Sin embargo, la retórica guerrerista y la violencia cierran las posibilidades de encuentro. El cuarto propio, en el sentido de la propiedad privada, fragmenta y se opone a la colectivización.

En este sentido, más que un cuarto en medio de la casa pareciera un condominio. En un condominio, se delimitan los espacios compartidos y se regulan de tal manera que no invitan, más bien excluyen. Es por excelencia el modelo de la propiedad privada, la aspiración burguesa que busca encerrarse en un ambiente hiperreglamentado y con pocos espacios de encuentro.

5 Ramirez y Castellanos afirman que "la solicitud de inscripción de Michel Riquelme al VIII ELFLAC fue aceptada por la Ekipa; previamente, envió una carta que cuenta su historia y explica la experiencia de su tránsito, así como su trayectoria en el activismo lésbico y feminista" (2013, 51). 
En el condominio, se puede vivir evitando el contacto y cerrando las puertas contra vecinos hostiles.

Desde una perspectiva interseccional, esta lógica supone algunas contradicciones. Por un lado, desde esta tendencia, de forma mucho más clara y contundente que desde el movimiento LesBiTransInter Feminista, como veremos, hay un esfuerzo por reflexionar sobre los privilegios, las opresiones y el poder, alrededor de preguntas del tipo: “Cómo definimos las relaciones como lesbianas feministas racializadas con las no racializadas; con los gays, Ixs trans, Ixs 'rarxs'; con lesbianas feministas rurales y urbanas; de distinta clase social y edades diversas; etc.?" (ELFLAC, 2014). Pero al mismo tiempo, al sostener la exclusión de las personas trans, no del espacio del encuentro, sino de la posibilidad de autodeterminación identitaria como lesbofeministas, se reproduce la opresión desde un lugar de privilegio y jerarquía, y se contribuye por rebote con la colonización de los cuerpos y las subjetividades desde las lógicas patriarcales de subordinación.

\section{Metáfora del jardín abierto}

Proponemos que en lugar de "cuartos propios" cerrados e inmutables, estos espacios de encuentro puedan ser enormes jardines donde proliferen las articulaciones entre diferentes, y no sus exclusiones

(Encuentro LesBiTrans de Latinoamérica y el Caribe, 2010, 1).

En el otro extremo, encontramos una corriente contestataria que se gesta a partir del malestar con las posturas restrictivas dentro de un sector del feminismo lésbico, y que culmina articulándose a partir de las situaciones vividas por Michel Riquelme durante el VIII ELFLAC, que se relatan en el apartado anterior, y que, en la actualidad, se organiza alrededor de los encuentros LesBiTransInter Feministas Venir al Sur. Esta corriente, adopta la metáfora del jardín abierto como espacio de libertad para la

construcción colectiva de ámbitos donde el acceso no esté signado por biologicismos ni esencialismos de ningún tipo y donde el "discurso de asamblea" no sea ni la única ni la principal forma de comunicarse, sino que podamos interpelar a nuestros cuerpos políticos, con sus afectividades y sus sentires más diversos, en una gama de lenguajes interactuantes que reflejen las vastas formas de transformación (Encuentro LesBiTrans de Latinoamérica y el Caribe, 2010, 1).

En contraste con la crítica que desde la interseccionalidad se propone en el apartado anterior, esta tendencia se plantea como eje central la búsqueda de espacios de encuentro y articulación desde distintas identidades (sin necesidad de borrarlas, pero aceptando que además de las identidades binarias existen otras, incluso fluidas y móviles).

Esta corriente destaca las particularidades y la diversidad de contextos desde donde se construye el feminismo lésbico, y critica las prácticas que 
durante el VIII ELFLAC pretendieron "evaluar con una vara universal y absoluta que mucho se parece al 'pensamiento único' las formas de desarrollo de los movimientos feministas y activismos lésbicos en cada uno de nuestros países" (Encuentro LesBiTrans de Latinoamérica y el Caribe, 2010, 2).

Sin embargo, una lectura interseccional de las comunicaciones oficiales de cara al encuentro Venir al Sur, devela el riesgo que corre este movimiento, cuando se encuentra tan concentrado en la defensa de los espacios abiertos e inclusivos (lo cual es comprensible luego de una experiencia de violencia) que se enreda y corre el riesgo de volverse monoaxial.

En este sentido, las discusiones sobre otras jerarquías de poder más allá de las que inscriben la identidad de género y la orientación sexual, como clase, raza, etnicidad, ruralidad o edad, si bien aparecen mencionadas, no tienen un peso central como lo tienen en los ELFLAC. Frente a la identidad de género y la orientación sexual, estas otras identidades aparecen desteñidas en un plano secundario.

Desde esta perspectiva, vale la pena analizar la metáfora del jardín abierto y lo que esta revela. La elección del sustantivo jardín, nos sugiere que esta metáfora se elaboró desde una perspectiva urbana. Según la Real Academia Española: jardín viene "(Del fr. jardin, dim. del fr. ant. jart, huerto, y este del franco *gard, cercado; cf. a. al. ant. gart, corro, ingl. yard, patio). Terreno donde se cultivan plantas con fines ornamentales".

Frente a vocablos como campo, finca, parque o predio, el jardín nos ubica en la lógica urbana, en un espacio agradable, pero inevitablemente limitado. Un jardín puede ser abierto, pero de igual forma implica un privilegio que pone en entredicho el potencial democratizador y horizontal de esa apertura.

El que este movimiento tenga un fuerte componente urbano, de activismo atravesado por la academia y/o por organizaciones vinculadas críticamente a la cooperación extranjera, es una realidad que no es reprochable por sí misma. Pero desde la interseccionalidad se esperaría un trabajo autocrítico del lugar de privilegio, con el fin de neutralizar, o al menos mitigar las dinámicas de opresión que le atraviesan.

Así, desde una perspectiva interseccional surge una serie de preguntas, que no deben leerse como cuestionamientos hostiles, sino como reflexiones de cara al desarrollo de espacios diversos e inclusivos: ¿a quién invitan y a quién incluyen estas convocatorias autoproclamadamente abiertas? ¿Qué públicos se sienten identificados y convocados a través de su lenguaje, su retórica y sus medios de circulación digitales, y qué públicos se encuentran excluidos? ¿Qué pasó con el reclamo de las feministas negras, sobre la blanquitud de estos encuentros? ¿Cómo es, en términos cuantitativos y cualitativos, la participación de lesbianas indígenas, de trans del campo? ¿Es este jardín tan abierto y tan diverso, o hay todavía cercas invisibles que impiden que nuevas flores vengan a poblarlo? 


\section{Centroamérica, entre el jardín y la habitación}

En medio de la discusión entre tendencias contrapuestas, surge la pregunta por Centroamérica, ¿cómo se viven estas discusiones en las cotidianidades centroamericanas? Y más allá de esto, ¿son estas sus discusiones?, ¿cómo se construye el feminismo lésbico centroamericano, cuáles son sus principales preocupaciones, sus líneas de acción, sus espacios de articulación?

Para ambas tendencias, resulta claro que el punto de inflexión que marca un antes y un después en los encuentros lésbico feministas se ubica en Guatemala, en el año 2010. Como se analiza en el apartado anterior, a partir de ese momento se han realizado reflexiones, críticas y pronunciamientos, que dan pie a la organización de dos encuentros (que ocurrieron de forma simultánea) en el año 2012 en Paraguay y en Bolivia.

Sin embargo, llama la atención que dentro de las publicaciones académicas y digitales que se encuentran sobre el tema, la presencia de voces centroamericanas es mínima en comparación con publicaciones escritas por feministas lesbianas de México y Suramérica. Esta baja participación centroamericana pudo observarse también en el encuentro LesBiTransInter Feminista Venir al Sur ${ }^{6}$ (posiblemente ligado al alto costo que implica viajar a Paraguay desde Centroamérica), donde la participación fue pequeña en comparación con otros países del sur. Sin embargo, en este contexto, se propone la realización del II Encuentro Venir al Sur en el año 2015 en Costa Rica, llamado a modo de broma "Venir al Centro", con el fin de facilitar la participación centroamericana.

En este contexto, reflexionar sobre el feminismo lésbico centroamericano cobra mayor importancia, no por un afán de clasificar las luchas por regiones en abstracto, sino porque la historia y las realidades actuales de Centroamérica crean condiciones de existencia particulares, que atraviesan y determinan las condiciones de opresión y las prácticas de resistencia desde el feminismo lésbico.

Así, sin intención de jerarquizar o minimizar, pero reconociendo las diferencias profundas entre los contextos, desde una perspectiva interseccional podemos afirmar que no es lo mismo autodenominarse lesbiana feminista en Matagalpa, Nicaragua, que en Montevideo, Uruguay, ser lesbiana feminista campesina en el Aguan, o ser migrante nicaragüense feminista lesbiana en Upala, Costa Rica; como no es igual ser trans en Tegucigalpa que en Buenos Aires, en los barrios del sur de San José de Costa Rica o en San Paulo, Brasil. Aunque compartan una misma raíz, las opresiones se materializan de formas distintas, y las herramientas para afrontarlas varían según el contexto.

Interesa entonces acercarse a las discusiones del feminismo lésbico centroamericano. Para efectos de este ensayo, se analizan dos documentos que

$6 \quad$ No se encuentran referencias sobre la participación centroamericana en el IX ELFLAC. 
constituyen la sistematización de encuentros realizados desde un enfoque feminista: el primero, realizado en el año 2012 como iniciativa de la organización MULABI, en el que confluían lesbianas y trans para dialogar y construir desde una perspectiva feminista, y el segundo, realizado en marzo del 2014 en Granada, Nicaragua, que convocó a lesbianas de la región para discutir desde el feminismo lésbico.

Como punto de partida, es importante señalar que existen importantes diferencias a lo interno de la región. En Costa Rica, por ejemplo, el feminismo ha estado muy ligado a la academia y a la institucionalidad (con algunas excepciones), y existen pocas organizaciones que se enmarcan desde una perspectiva de lucha lesbofeminista (Torres, 2014). Países como Nicaragua o El Salvador, por el contrario, tienen una importante presencia de organizaciones sociales lésbicas que se autodenominan como, o bien dialogan con, el feminismo lésbico. Estas diferencias tienen como resultado una diversidad de necesidades, enfoques y prioridades, que se evidencian en las discusiones de los encuentros (MULABI, 2012).

En el Encuentro Lésbico-Feminista Centroamericano (Granada, 2014), el tema de la inclusión de personas trans no se incluyó en la agenda, aunque fue un emergente constante en algunas discusiones, en especial de la mano de participantes de Costa Rica que forman parte de la organización del Encuentro Venir al Sur 2015 (Torres, 2014). Sin embargo, no fue el eje central (como lo fue en el VIII ELFLAC), y en cambio, otros temas se dibujaron como prioritarios:

La necesidad de construir teoría y estadísticas desde Centroamérica, generando conceptos que den cuenta de estas realidades.

La importancia de que la construcción desde el feminismo se haga de forma horizontal, con la gente y no sobre la gente, para romper con la lógica colonial de la epistemología.

La riqueza de una nueva generación de investigadoras que también son activistas, y pueden tender puentes entre lo académico y la calle.

El reconocimiento, como un logro del movimiento, de la incorporación de voces feministas en los movimientos LGBTI.

La importancia de pensar críticamente las jerarquías que la edad impone, en forma de adultocentrismo y edadismo.

La dificultad que implica el trabajo con recursos limitados, que impide la construcción de estrategias y obliga a trabajar en esfuerzos individuales y desarticulados.

La necesidad de contar con una plataforma articulada de acción, intercambio de recursos y experiencias, que permita colectivizar herramientas y conocimientos.

La importancia del trabajo autocrítico de los liderazgos y las relaciones de poder, acompañados por el reconocimiento de la necesidad de estrategias de autocuido para romper con las lógicas sacrificiales del activismo heredadas del modelo patriarcal. 
El reto por articularse con otros movimientos sin perder la perspectiva del horizonte lésbico (síntesis realizada a partir de Torres, 2014).

A modo de resumen, la pregunta central que parece tejer estas inquietudes es cómo hacer para que las prácticas de resistencias y construcción de conocimiento desde el feminismo lésbico centroamericano, no reproduzcan las jerarquías de poder centro-periferia, academia vs. activismo, la priorización de unos saberes, la acumulación de conocimiento en lugar de su transmisión, el adultocentrismo, los protagonismos y el activismo sacrificial. Y cómo hacer para generar espacios lésbico-feministas inclusivos para la diversidad de subjetividades que existen en la región.

En cuanto a espacios de encuentro entre lesbianas y trans, en el 2012 MULABI organizó en Managua los Diálogos "Construyéndonos": un esfuerzo por acercar a activistas centroamericanas al feminismo. Para algunas de las participantes constituyó el primer encuentro de esta índole donde compartían con personas trans y lesbianas (MULABI, 2012).

Entre los temas discutidos, aparecen los puntos de encuentro y desencuentro entre lesbianas y trans. Se plantea que muchas mujeres lesbianas no se sienten identificadas con la lucha de las mujeres trans y tienen diferencias con temas como el trabajo sexual y la forma en que muchas trans construyen su feminidad. Las trans reclaman a las lesbianas una postura demasiado fijada en el binomio hombre-mujer y las invitan a pensar otras propuestas como la existencia trans (MULABI, 2012).

Desde acá, se construyeron discusiones en torno a la construcción del ser mujer y de la feminidad, y las posibilidades de cuestionar los lugares impuestos y de reinventar formas de vivir la feminidad y la masculinidad. Señalan la importancia de romper con los estereotipos que vinculan las estéticas y expresiones de género masculinas con posturas y prácticas machistas. Se habla del peso de los estereotipos y los mandatos en torno a cuestiones como la vestimenta, el maquillaje, el largo del cabello, que con frecuencia se convierten en normatividades que imponen lo que debe y no debe ser (MULABI, 2012).

Entre los puntos de encuentro, señalan la lucha contra la discriminación y los prejuicios, la violencia misógina, y las soledades. Surge el tema del derecho a la maternidad como una discusión pendiente, para aquellas lesbianas y trans que quieran ejercerla (MULABI, 2012). Surgen algunas reflexiones sobre la interseccionalidad, en torno a las diferencias que caracterizan la cotidianidad de lesbianas que viven en zonas rurales y urbanas, o la forma en que la condición de clase complica las condiciones de existencia de las trans (MULABI, 2012).

En torno al feminismo, se desarrolló una discusión a partir de una exposición sobre la historia del feminismo y los distintos feminismos que existen. Las posiciones fueron variadas. Algunas afirmaron no sentirse cercanas ni representadas por ningún feminismo, mientras otras defendían la necesidad de pensar en feminismos inclusivos e igualitarios (MULABI, 2012). 
Se habla del feminismo como vivencia, como estrategia y como escuela para los sectores oprimidos. Muchas organizaciones trans, se afirma, han surgido a partir de grupos feministas. Desde esta perspectiva, se rescata la importancia de asumir prácticas feministas y construir, desde ahí, los feminismos que respondan a las necesidades de la región y de cada sector. De forma autocrítica, se reconoce que en la discusión con las feministas que se oponen a la inclusión de personas trans no se han tendido puentes de diálogo. "¿Cuál es la propuesta alternativa? ¿Qué proponemos frente a eso? Tenemos que escribir, generar nuestra propia realidad" (MULABI, 2012, 11).

Tomando el feminismo como estrategia, el grupo concordó con la necesidad de reconocerse como punto de partida para el trabajo conjunto. "Acá todas somos mujeres, pero no tenemos las mismas necesidades, son diferentes. Los derechos son iguales pero las prioridades son distintas" (MULABI, 2012, 17). Los espacios de visibilidad lésbica son necesarios aún cuando se articulen luchas con las trans y vicerversa. En este sentido, se propone reconocer los puntos que unen a las lesbianas y trans, y los puntos que las hacen diferentes, no para jerarquizar y establecer niveles, sino para articular las reflexiones y las luchas en el contexto centroamericano.

En un juego con las metáforas analizadas en el apartado anterior, podría decirse que desde esta posición, se reconoce la necesidad de cuartos propios, pero también de un jardín donde sea posible sembrar y cultivar luchas articuladas.

\section{Conclusiones: metáfora del río}

"De hecho, las mujeres trans nos llevamos mejor con las mujeres lesbianas"

(MULABI, 2012, 22)

Planteaba Freud (1919) en Lo Siniestro, que a veces aquello que más nos aterroriza del otro o la otra, es precisamente lo que nos resulta familiar. Es la contradicción que revela esta afirmación hecha por una activista trans en los Diálogos "Construyéndonos". Hay coincidencias que acercan a lesbianas y trans feministas: el cuestionamiento al ser mujer y la construcción de la feminidad desde el patriarcado, y la reconstrucción que se hace desde una perspectiva feminista sobre el cuerpo político.

La interseccionalidad, como herramienta de análisis promovida por el feminismo negro, no propone el borramiento de las identidades desde un lugar posmoderno y despolitizado. Lo que propone es el reconocimiento de que las múltiples lógicas de opresión (como clase, raza, género, sexualidad), si bien son distintas, están profundamente imbricadas en un tejido que aprieta sobre los cuerpos y las subjetividades recrudeciendo sus condiciones de existencia (Lugones, 2008, 2012). Si se busca luchar contra la opresión de las mujeres lesbianas desde una perspectiva feminista, es necesario comprender que esta lucha es específica, pero está íntimamente ligada a la lucha de las feministas negras 
contra el racismo, de las mujeres empobrecidas contra el capitalismo, y de las personas trans contra la violencia de género del sistema heteropatriarcal.

Desde una perspectiva interseccional no se propone botar las paredes y eliminar los cuartos propios, pero se destaca la necesidad de que existan espacios de encuentro abiertos y horizontales, donde se construyan luchas y resistencias, sin perder las particularidades, pero entretejiendo un frente articulado.

En línea con esta construcción discursiva, se puede proponer otra metáfora para pensar los feminismos lésbicos: un río. En cada orilla del río hay playas, bancos de arena, espacios donde se puede construir. Estas playas serían el terreno para las identidades, algo así como el homólogo natural del cuarto propio. Más allá de las orillas, un bosque profundo y espeso, donde crecen múltiples identidades que se acercan con diversas intenciones a las playas. Y el río, ese lugar en el que el poder fluye en intensas corrientes que forman remolinos y arrastran piedras. Distintos cuerpos y subjetividades se sumergen en el río, algunos se resisten a dejarse llevar por la fuerza de la imposición y la costumbre, y se atreven a nadar contracorriente. Pero nadar a contracorriente en soledad es desgastante. Se necesitan puentes, alternativas que permitan articular las resistencias colectivas contra las corrientes. $Y$ para tender puentes, se necesitan las playas, ese lugar de la especificidad identitaria que será la base para las estructuras que unan una orilla con la otra.

Las playas, los puentes y hasta las aguas del río son espacios de construcción desde los feminismos radicales, para resistir los embates de las múltiples corrientes de opresiones que se intersecan y se potencian. Sin las playas no son posibles los puentes, y sin ellos muchas personas serían arrastradas por la corriente.

De cara al encuentro Venir al Sur 2015 y a las posibilidades que este abre para la construcción colectiva en la región, pensar los feminismos lésbicos alrededor de la metáfora del río, invita a imaginar un escenario donde la propuesta de espacios propios se articule con la necesidad de espacios de encuentro.

\section{Referencias}

Anneliese Singh, Kate Richmond y Theodore Burnes. (2013). Feminist Participatory Action Research with Transgender Communities: Fostering the Practice of Ethical and Empowering Research Designs. International Journal of Transgenderism. Recuperado de http://www.tandfonline.com/loi/wijt20

Butler, Judith. (2006). Deshacer el género. Barcelona: Paidos.

Comisión de Metodología y Contenidos Venir Al Sur. (2011). Ruta Metodológica. Recuperado de http://veniralsur.files.wordpress.com/2012/06/rutametodologica-de-venir-al-sur-20121.pdf 
Fairclough, Norman. y Wodak, Ruth. (1997). Análisis crítico del discurso. En Van Dijk, T. (Comp). El discurso como interacción social. Barcelona: Editorial Gedisa.

Foucault, Michel. (1993). Curso del 7 de enero de 1976. En Microfísica del poder. Madrid: Editorial La Piqueta.

Freud, S. (1919). Lo siniestro. Buenos Aires: Editorial Biblioteca Nueva.

Ekipa Guatemala. (2010a). BoletínA La Tambora. Recuperado de http://issuu. com/elflac/docs/elflac_boletina

Ekipa Guatemala. (2010b). Reflexiones Políticas sobre el encuentro. VIII Encuentro Lésbico Feminista Latinoamericano y Caribeño. Hilando rebeldías lésbicas feministas desde la raíz. Recuperado de http://elflacguate.blogspot.com/

ELFLAC. (2014). BOLETINA No 3: Propuesta político-metodológica. X Encuentro Lésbico-Feminista De Abya Yala. Recuperado de http://elflac.org/wp-content/uploads/2014/04/Propuesta-pol\%C3\%ADticometodol\%C3\%B3gica.pdf

Encuentro LesBiTransInter Feminista de Latinoameirica y el Caribe. (2010). Construyendo Feminismo sin paredes. Todas las voces, todas las formas, todos los cuerpos, todas las prácticas. Recuperado de http://www.aireana. org.py/encuentro_LesBiTrans_Feminista.html

Espinosa, Yuderkis. (2012). La política sexual radical autónoma, sus debates internos y su crítica a la ideología de la diversidad sexual. En Pensando los feminismos en Bolivia. Recuperado de http://www.conexion.org.bo/archivos/pdf/FEMINISMO.pdf

Grosfoguel, Ramón. (2011). La descolonización del conocimiento: diálogo crítico entre la visión descolonial de Frantz Fanon y la sociología descolonial de Boaventura de Sousa Santos. En IV Training Seminar de jóvenes investigadores en Dinámicas Interculturales. Recuperado de http://www.cidob.org/es/content/download/29942/356572/file/97-108_ RAMON+GROSFOGUEL.pdf

Lakoff, George y Johnson, Mark. (1995). Metáforas de la vida cotidiana. Madrid: Cátedra.

Lugones, María. (julio-diciembre, 2008). Colonialidad y género. Tabula Rasa, 9, 73-101.

Lugones, María. (2012). Subjetividad esclava, colonialidad de género, marginalidad y opresiones múltiples. En Pensando los feminismos en Bolivia. Recuperado de http://www.conexion.org.bo/archivos/pdf/FEMINISMO.pdf 
Mogrovejo, Norma. (2012). Encuentros lésbicos, transgeneridades y biopoder. Recuperado de http://normamogrovejo.blogspot.com/2012/11/encuentroslesbicos-transgeneridades-y.html

Mogrovejo, Norma. (2010). Los encuentros lésbicos feministas latinoamericanos y del Caribe en la era del postfeminismo. Revista Digital Universitaria, 11 (9). Recuperado de www.revista.unam.mx/vol.11/num9/art86/art86.pdf

MULABI. (2012). Memoria de los Diálogos "Construyéndonos”, Nicaragua 2012. Recuperado de: http://www.mulabi.org/memorias/site/home.html

Rachid, María; Espinosa, Yuderkis y Gonorasky, Sonia. (2008). Lesbofeminismo. En Despertando a Lilith. Recuperado de http://www.despertandoalilith.org/?p=156

Ramírez, Ana Lucía y Castellanos, Gabrielle. (2013). Autorizar una voz para desautorizar un cuerpo: producción discursiva del lesbianismo feminista oficial. ĺconos. Revista de Ciencias Sociales, 45.

Real Academia Española. (2001). Diccionario de la lengua española (22. aed.). Consultado en http://www.rae.es/rae.html

Rubin, Gayle. (1986). El Tráfico de las Mujeres: Notas sobre la Economía Política del Cuerpo. En Lamas, Marta. (Comp.) El género la construcción cultural de la diferencia sexual.

Torres, Luz Paulina. (2012). Formulación de una propuesta para fortalecer el trabajo de incidencia política de la organización Colectiva por el Derecho a Decidir-CPDD, dirigido a las mujeres lesbianas. Proyecto de Investigación para optar por el grado de Licenciatura en Sociología. Universidad de Costa Rica

Torres, Luz Paulina. (2014). Sistematización del Encuentro Lésbico Centroamericano. Granada, 2014. (Documento inédito).

Van Dijk, T. (1990). La noticia como discurso. Comprensión, estructura y producción de la información. España: Paidos.

Wittig, Monique. (2006). El pensamiento heterosexual y otros ensayos. Madrid: EGALES.

Woolf, Virgina. (1989). A room of One's Own. Estados Unidos: Harcourt. 